\title{
Non-Invasive Ventilation and Surfactant Therapy
}

\author{
Rangasamy Ramanathan*, Pedro Paz, and Manoj Biniwale
}

Division of Neonatal Medicine, LAC+USC Medical Center and Children's Hospital of Los Angeles, Keck School of Medicine, University of Southern California, USA

\begin{abstract}
The lungs of premature infants are more vulnerable than term infants to the effects of invasive positive pressure ventilation. Published literature supporting the use of non-invasive respiratory support with CPAP, bi-level CPAP mode, such as, SiPAP and Nasal Intermittent Positive Pressure Ventilation (NIPPV), and surfactant administration strategies are discussed. This review focuses on non-invasive respiratory support strategies and selective early use of surfactant that may reduce the incidence of bronchopulmonary dysplasia.
\end{abstract}

Keywords: Respiratory distress syndrome; Prematurity; Noninvasive respiratory support; Non-invasive positive pressure ventilation; CPAP; Surfactant; Bronchopulmonary dysplasia

\section{Invasive Ventilation}

Bronchopulmonary Dysplasia (BPD) remains major pulmonary morbidity in preterm infants with Respiratory Distress Syndrome (RDS), especially among the Extremely Low Birth Weight (ELBW) infants, [1] and is associated with short- and long-term adverse pulmonary and non-pulmonary outcomes. Advances in perinatal care, including antenatal corticosteroid use, advances in invasive mechanical ventilation modes, and postnatal surfactant therapy have significantly decreased the severity of RDS and neonatal mortality. Despite these changes, invasive ventilation via an endotracheal tube remains as one of the major reasons for the development of BPD. Prophylactic or rescue surfactant therapy alone has not been shown to decrease BPD rate. Noninvasive respiratory support modes, especially bilevel CPAP or SiPAP mode, have not been shown to impact BPD rate. However, use of early, rescue surfactant therapy and NIPPV mode has been shown to decrease BPD rate. This review will focus on the benefits of surfactant therapy used in combination with NIPPV mode of respiratory support in preterm infants.

\section{Invasive Ventilation Modes}

\section{Pressure versus volume targeted ventilation}

Ventilator induced lung injury is related to several factors. Barotrauma was initially thought to be the major contributing factor leading to lung injury [2]. However, studies from the 1980s showed that volutrauma is a major cause of lung injury $[3,4]$. Since then, several advances have been made in mechanical ventilation, particularly in Intermittent Mandatory Ventilation (IMV) modes, such as, Synchronized IMV (SIMV), and volume targeted or Volume Guarantee (VG) modes of ventilation. The world's first pediatric volume ventilator was studied in 90 neonates by Kirby et al. [5] in 1971. In this study, overall survival was $60 \%$, with the smallest surviving infant weighing $950 \mathrm{~g}$ at birth. The first randomized controlled trial comparing pressure versus volume controlled ventilation in neonates was published in 1978 . In this small study $(n=20)$, Manginello et al. [6] concluded that pressure controlled ventilation was significantly better than volume controlled ventilation. Pressure targeted ventilation remains the most common mode of ventilation currently used by many neonatal intensive care units (NICUs) in USA [7]. Only 12 randomized, trials comparing volume targeted versus pressure targeted modes of ventilation have been published to date [8]. Reasons for using this mode of ventilation include: unfamiliarity with volume targeted modes, need for use of a flow sensor to target exhaled tidal volumes, and variable leaks around the uncuffed endotracheal tubes used in neonates that make it difficult to target tidal volumes precisely. Recent studies comparing pressure limited versus volume targeted modes of ventilation have shown a significant decrease in BPD, death or BPD as a composite outcome, less days on mechanical ventilation, less air leaks, and decreased incidence of hypoventilation with volume targeted modes of ventilation [8].

\section{High frequency ventilation}

High Frequency Oscillatory Ventilation (HFOV) using subphysiological tidal volume at supra-physiological rates was introduced in the 1990s in an attempt to reduce volutrauma. Several meta-analyses published since then have shown no significant difference in BPD rates between SIMV and HFOV, when HFOV was used as a primary mode of ventilation in preterm infants with RDS [9-11]. In patients failing conventional mechanical ventilation, high frequency ventilation may be used as a rescue mode.

\section{Invasive ventilation and lung injury}

In patients requiring invasive ventilation, volume targeted or VG modes may be better options for reducing lung injury. Use of low- and high-tidal volume ventilation is associated with lung injury. Mechanical stretching of lung cells, regardless of the tidal volume used, elicits a complex network of signaling molecules and specific cellular responses, known as, mechanotransduction [12]. Recent studies have shown that even noninjurious mechanical ventilation using normal tidal volumes activates a proinflammatory transcriptional program in the uninjured lung, which can prime the lung for injury [13]. Invasive mechanical ventilation not only initiates a pulmonary inflammatory response, but also a systemic inflammatory response in preterm infants [14]. The preterm infant lung is more vulnerable during the transitional period soon after birth. Preterm infants ventilated for more than 7 days after birth have more elevated concentrations of proinflammatory cytokines and chemokines in their blood than those ventilated for less than 7 days.

Invasive ventilation inducesa systemic inflammatory response, which may be responsible for the increased risk for adverse neurodevelopmental outcomes in preterm neonates with BPD.

*Corresponding author: Rangasamy Ramanathan, USC Division of Neonatal Medicine, LAC+USC Medical Center and Children's Hospital Los Angeles 1240, North State Street, IRD-820, Los Angeles, CA 90033, USA, E-mail: ramanath@usc.edu

Received July 18, 2012; Accepted September 11, 2013; Published September 13, 2013

Citation: Ramanathan R, Paz P, Biniwale M (2013) Non-Invasive Ventilation and Surfactant Therapy. J Pulmon Resp Med S13: 006. doi:10.4172/2161-105X.S13006

Copyright: $(2013$ Ramanathan R, et al. This is an open-access article distributed under the terms of the Creative Commons Attribution License, which permits unrestricted use, distribution, and reproduction in any medium, provided the original author and source are credited. 
Increased concentrations of serum proinflammatory cytokines on day of life 7 and 14 predict severe neurodevelopmental impairment at 2 years of age in ELBW infants [15]. The risk for white matter injury increases fivefold in preterm infants with BPD. Furthermore, invasive ventilation for 7 days increases the risk for BPD by 8 -fold, compared to non-ventilated infants [16]. Another study showed that mechanical ventilation for only 2 hours in preterm infants not only increased proinflammatory cytokines, like interleukins (IL) 6 and 8, and tumor necrosis factor- $\alpha$, but also significantly decreased the levels of the antiinflammatory cytokine IL-10 in the serum [17]. Laughon et al. [18], in an effort to predict BPD based on respiratory support requirement at a specific postnatal age, identified that mechanical ventilation by day of life 7 increased the risk of BPD by 4-8 fold when compared to Continuous Positive Airway Pressure (CPAP) in preterm infants less than 30 weeks gestational age.

\section{The new BPD}

A preterm infant's lungs, with both anatomical and functional immaturity as well as surfactant deficiency, are more vulnerable to injury during the transitional period soon after birth. Risk for BPD is inversely proportional to gestational age and birth weight. Preterm infants who develop BPD are born at the canalicular stage of lung development and lack both saccules and alveoli. Even a few large inflations immediately after birth can initiate lung injury due to the release of proinflammatory cytokines $[19,20]$. Persistent inflammation leads to aberrant healing and repair of the developing lung, resulting in alveolar and vascular hypoplasia, which are the hallmarks of the "new" BPD. Maternal chorioamnionitis can lead to a fetal inflammatory response syndrome, which results in the release of fetal proinflammatory cytokines, making it vulnerable to lung injury when exposed to postnatal interventions, such as, mechanical ventilation and oxygen therapy. Response to surfactant therapy is blunted in such situations of lung inflammation, and these patients may require early surfactant administration, use of higher doses of surfactant, or a surfactant that resists inactivation by the inflammatory mediators [21].

\section{Non-Invasive Ventilation}

In an attempt to reduce lung injury, Noninvasive Ventilation (NIV) has been used for the past 3 decades [22]. Delivery of adequate respiratory support with NIV involves pressure generators, patient nasal interfaces and the ability to provide one or two levels of pressures at different frequencies. Three of the most common modes of NIV are NCPAP, SiPAP, and NIPPV [23].

\section{NCPAP}

NCPAP reduces upper airway resistance, maintains functional residual capacity, decreases chest wall distortion, augments spontaneous breathing efforts, preserves endogenous surfactant, decreases the need for exogenous surfactant administration, and decreases the need and/ or duration of invasive ventilation [24,25]. Prolonged NCPAP used to minimize supplemental oxygen administration and to promote lung growth $[26,27]$, has been suggested to be one of the potentially better practices that may improve pulmonary outcomes [28]. NCPAP is generated by using constant or variable flow devices. NCPAP may be provided using a water column (bubble CPAP), a flow generator (Infant flow driver), or a conventional ventilator. The pressure generated in all these systems is flow dependent. Bubble CPAP systems use a constant gas flow rate that is set by the user, and the CPAP generated is equal to the length of expiratory tubing that is immersed under water. Even during bubble CPAP, increasing the flow rate will also increase the intra-prong pressures at the level of the patient's nasal interface. Typical flow rates used during bubble CPAP are between 6-10 liters per minute $(\mathrm{pm})$. Infant flow drivers are variable flow devices that generate two levels of pressure (a high pressure or peak inspiratory pressure [PIP], and a low pressure or positive end-expiratory pressure [PEEP]) by varying the flow rates. These devices use a dedicated flow driver and generator with a patented fluidic flip mechanism that allows variable flow rates throughout the respiratory cycle. This mechanism, also known as the Coanda effect provides stable baseline pressures and has been shown to decrease expiratory work of breathing [29,30]. No back up rate is provided during NCPAP. Studies comparing different means of providing NCPAP have shown no difference in extubation failure rates [31-33]. In patients with hypopnea or apnea, failure rates with NCPAP are high, and require intubation or reintubation.

\section{Bi-level NCPAP}

Bi-level CPAP, also known as, SiPAP or BIPAP or biphasic CPAP, is another form of CPAP that generates two levels of pressure and allows spontaneous breathing during both levels of pressures. Flow generators are used to deliver two levels of pressure (PIP and PEEP) during SiPAP. However, this mode of respiratory support is significantly different than NIPPV mode. Major differences between SiPAP and NIPPV modes include, limited ability to deliver PIP $\left(\sim 10 \mathrm{cms} \mathrm{H}_{2} \mathrm{O}\right)$, lower delta pressures (PIP-PEEP: $\sim 3-4 \mathrm{cms} \mathrm{H}_{2} \mathrm{O}$ ), use of longer inspiratory times (ITs $\sim 0.5$ to $1 \mathrm{~s}$ ) and need for using high flow rates to generate PIP during SiPAP. SiPAP mode is similar to CPAP, except for back up rates with much lower PIP. On the contrary, NIPPV mode mimics invasive mode of respiratory support. During NIPPV, PIP applied can be as high $30 \mathrm{cmsH}_{2} \mathrm{O}$ or more, and typically delta pressure is greater than $5 \mathrm{cmsH}_{2} \mathrm{O}$ and shorter ITs ( $\left.0.3-0.5 \mathrm{~s}\right)$ are used. Failure rates needing intubation or reintubations during SiPAP are similar to NCPAP. [34] In this large, randomized trial involving 1,009 extremely low birth weight infants with a birth weight $<1000 \mathrm{~g}$, postrandomization failures needing intubation were $59.5 \%$ in the SiPAP group and $61.8 \%$ in the NCPAP group. This is the first study that reported such a high incidence of failure rates with what the study authors had called as NIPPV mode. Most patients assigned to the NIPPV group in fact were treated with SiPAP. Investigators had also limited the PIP to $18 \mathrm{cmsH}_{2} \mathrm{O}$ in the SiPAP/NIPPV group. Unfortunately, the authors called the SiPAP mode as NIPPV mode in this study. As a result of high failure rates, there was no difference in BPD rates between SiPAP and NCPAP modes of noninvasive ventilation strategies [34].

\section{NIPPV}

Provision of a back up rate plus two levels of pressure, namely, PIP and PEEP during NIPPV, has been shown to significantly decrease the need for intubation or re-intubation. Minimizing the duration of invasive ventilation by using NIPPV has also been shown to decrease BPD [23]. Interfaces used during NIV include face mask and nasal prongs. Bi-nasal prongs have been shown to be more effective than a single prong in providing NIPPV [35].

\section{High Flow Nasal Cannula}

High Flow Nasal Cannulas (HFNC) are increasingly used because of their ease of use. However, very high pressures can be generated when flow rates higher than $2 \mathrm{lpm}$ are used. Even at $21 \mathrm{pm}$, the CPAP generated may be as high as $10 \mathrm{~cm} \mathrm{H}_{2} \mathrm{O}$ [36]. Serious complications, such as scalp emphysema, pneumoorbitis, and pneumocephalus have been reported with use of HFNC [37]. Since pressures generated are neither measured nor controlled by the user, flow rates more than $2 \mathrm{lpm}$ should be not be used in preterm neonates. 


\section{NIV in the Delivery Room}

Any attempt to provide lung protective strategies should begin immediately after birth. Establishment of functional residual capacity with CPAP is the most important step during the initial stabilization period in preterm infants [38]. Even few breaths with large inflations can trigger lung injury [39]. The current neonatal resuscitation program guidelines recommend using a t-piece device to deliver consistent CPAP, rather than using a self-inflating or flow-inflating bag $[40,41]$. Bag and mask resuscitation has also been shown to result in significant mask leaks and airway obstruction [42-44]. Three major issues with bag and mask ventilation are; mask leaks, upper airway obstructions caused by inadvertently pushing the tongue and soft tissues posteriorly, and the increase in dead space caused by the accumulation of gas in the oropharynx that is not contributing to gas exchange. Cappaso et al. [45] compared face mask with nasal cannula during primary neonatal resuscitation in a large randomized, controlled trial and concluded that nasal cannula was more effective than bag and mask ventilation in the delivery room. We have reported our results using a specially designed nasal cannula (Neotech RAM Nasal Cannula) in an observational study involving 102 neonates requiring respiratory support at birth [46].

\section{Sustained Inflation}

Sustained inflation (SI) has been studied in preterm infants in order to augment the beneficial effects of CPAP in the delivery room. Lindner and colleagues [47] reported a significant reduction in the rate of intubation in the delivery room (from $84 \%$ to $40 \%$ ), and an increase in the proportion of ELBW infants not needing intubation and invasive ventilation (from $7 \%$ to $25 \%$ ) after the introduction of a series of interventions at birth that included providing a 15 second SI at pressures of 20 to $30 \mathrm{~cm} \mathrm{H}_{2} \mathrm{O}$. Several small studies have shown that use of SI results in less need for surfactant therapy, less days on supplemental oxygen and mechanical ventilation, and less BPD in moderately preterm infants [48,49]. A large, multicenter, randomized trial to study the impact of SI on long-term outcomes is currently underway [50].

\section{NIV in the NICU}

NIV in the NICU can be provided through NCPAP or NIPPV either as a primary mode of respiratory support or following a period of invasive ventilation. NIV can also be used in infants after selective surfactant treatment using the INSURE (INtubation, SURfactant and Extubation) technique.

\section{NCPAP in the NICU}

Preterm infants stabilized with NCPAP or NIPPV in the delivery room can be continued on NCPAP after transport to the NICU. Several randomized controlled trials comparing NCPAP versus routine intubation in the delivery room have been published. Evidence from these studies show that NCPAP with or without surfactant therapy is as effective as routine intubation with or without surfactant treatment in preterm infants. None of these studies demonstrated a significant reduction in death or BPD. The COIN trial [51] randomized 610 spontaneously breathing infants who were between 25 and 28 weeks gestational age and who also had signs of respiratory distress at 5 minutes of life, to receive either CPAP or endotracheal intubation. Infants intubated due to respiratory distress before 5 minutes of age were excluded. NCPAP of $8 \mathrm{~cm} \mathrm{H}_{2} \mathrm{O}$ was used in this study. More infants treated with NCPAP developed pneumothorax (9\% versus 3\%). There was no difference in the primary outcome, namely, death or BPD between the 2 groups. The SUPPORT trial [52] from the United States randomized 1,316 infants between 24 and 28 weeks gestational age to receive NCPAP or endotracheal intubation and surfactant. Overall mortality and BPD rates were similar between the NCPAP and the intubation and surfactant group. In the Delivery Room Management trial [53], infants born between 26 and 29 weeks gestational age were randomized to NCPAP, to intubation-surfactant-extubation within 30 minutes to NCPAP, or to intubation for prophylactic surfactant and mechanical ventilation for at least 6 hours. This study was stopped early after 648 of a planned sample size of 876 had been enrolled. There were no differences in death or moderate to severe BPD (NCPAP $4.1 \%$ vs intubation- surfactant-extubation $7 \%$ vs prophylactic surfactant $7.2 \%$ ) and in pneumothorax rates (5.4\% vs 3.2 vs $4.8 \%$ ) between these 3 groups. Recently, a multicenter, randomized trial from the South American Neocosur Network showed that, early bubble CPAP and selective surfactant administration by the INSURE technique reduced the need for mechanical ventilation and surfactant, but showed no difference in the rates of death or BPD [54]. A major reason for the lack of benefit seen in these trials is secondary to the high rates of NCPAP failures, requiring intubation within 3-7 days of randomization. Essentially, these studies may be considered as study of early versus delayed intubation. The most common reasons for NCPAP failures are recurrent apnea, bradycardia or desaturation episodes, hypopnea, need for higher pressures (NCPAP $>8 \mathrm{cms} \mathrm{H}_{2} \mathrm{O}$ ), and/or severe respiratory acidosis. NCPAP when used as a primary mode, or following a period of invasive ventilation has been shown to result in failure rates of $19.7 \%$ to $80 \%$, needing intubation or re-intubation in preterm infants [23].

\section{NIPPV in the NICU}

To improve the efficacy of NIV, the NIPPV mode is being used increasingly in many centers. The five variables adjusted during NIPPV are: rate, PIP, PEEP, IT and flow rate. Spontaneous inspiratory effort is augmented when a patient receives a positive pressure breath during NIPPV [55]. Typical rates used during NIPPV range from 2040 breaths per minute. However, use of higher rates results in better respiratory unloading as compared to lower rates during synchronized NIPPV [56]. The recommended PIP during NIPPV varies from 15-20 $\mathrm{cmH}_{2} \mathrm{O}$ above the PEEP. Due to the high resistance found in the nasal interfaces, the pressure transmitted to the hypopharynx is always lower than the set pressures. Since the time constant becomes longer due to higher resistance in the circuit, a longer inspiration time ( 0.5 seconds) is recommended to transmit pressures set on the ventilator. Many ventilators are now available that have a built in mode for providing NCPAP or NIPPV. These ventilators adjust flow rates automatically. Leak compensation is also available for most NIV modes and should be turned on. In conventional mechanical ventilators without the NIV mode, flow rates of $14-20 \mathrm{lpm}$ are often needed to compensate for leaks while using NIPPV. For all practical purposes, NIPPV is a time cycled, pressure limited mode of ventilation, mimicking invasive mode of ventilation. Both synchronized and non-synchronized modes of NIPPV have been studied. At the present time, there are no devices in the United States that are capable of providing synchronized NIPPV. However, there are devices available in other parts of the world where flow synchronization as well as the use of a Graseby capsule to sense the changes in impedance are used to provide synchronized NIPPV, and are available for clinical use. Nine randomized, controlled trials comparing NCPAP versus NIPPV have been published to date [22,57-64]. Seven of the 9 trials showed a significant reduction in extubation failures with NIPPV, and 3 of the studies that used NIPPV as a primary mode of respiratory support and selective surfactant administration also resulted in lower rates of BPD when compared to NCPAP. Guidelines for use of NIPPV for clinicians have been published elsewhere [65]. 


\section{Nasal Interfaces During NIV}

Nasal interfaces commonly used for NCPAP or NIPPV include short binasal prongs, naso-pharyngeal prongs, and nasal masks. These interfaces are difficult to secure, which may further limit the handling of sick patients, and are also associated with a high incidence of nasal injuries, such as, columellar necrosis and nasal deformities $[66,67]$. We have experience using a specially designed nasal cannula (Neotech RAM Nasal Cannula) to provide NCPAP as well as NIPPV in the delivery room and in the NICU in over 500 patients, for over 5,000 days with an extremely low incidence of nasal injuries [68]. Suggested guidelines for starting NIV modes and for weaning to low flow nasal cannula using this specially designed nasal cannula are shown in Table 1.

\section{Neurally Adjusted Ventilatory Assist (NAVA)}

NAVA is a newer mode of ventilation that utilizes the electrical activity of the diaphragm by using a special nasogastric tube embedded with electrodes to provide synchronized breaths. This technology overcomes some of the issues associated with pressure or flow synchronized modes of ventilation, such as, inconsistent triggering due to variable leaks, and lack of inspiratory as well as expiratory synchronization of the patient triggered breaths. Briefly, an electrical signal is generated in the respiratory center of the brain stem, which travels via the phrenic nerve to stimulate the diaphragm. The electrical activity of the diaphragm is detected by the electrodes, which transmit the signal to the ventilator. The ventilator assists the spontaneous breath by delivering a proportional pressure. The PIP delivered is proportional to the amount of electrical activity generated by the diaphragm. The initiation, duration, size and termination of breaths are controlled by the patient, and thus, potentially offering full synchronization [69]. Stein et al. [70] reported in a retrospective study that preterm infants managed on NAVA mode maintained better blood gases using lower PIP and $\mathrm{FiO}_{2}$ values when compared to SIMV plus pressure support (SIMV+PS) mode of ventilation. Lee et al. [71] also recently reported in a randomized crossover study that NAVA lowered required PIP values and reduced the respiratory muscle load in preterm infants when compared to SIMV+PS. NAVA mode is also available for use in with noninvasive ventilation (NIV-NAVA). However, there are currently no studies showing the utility of the NIV-NAVA mode in preterm infants.

\section{Surfactant Therapy}

RDS due to surfactant deficiency is the most common cause of respiratory failure in preterm infants. Exogenous surfactant therapy has been extensively studied in preterm infants with RDS. Surfactant therapy has been shown to significantly decrease pneumothoraces, and mortality in neonates and infants [72]. Synthetic, as well as animal derived surfactants have been evaluated in several, randomized controlled trials [73]. Animal derived surfactants result in faster weaning of oxygen and mean airway pressure, shorter duration of invasive ventilation, and decreased mortality when compared to synthetic surfactants. In the 1990s, surfactant was administered as either prophylaxis (less than 15 minutes after birth), or as an early (within 2-6 hours of age) versus delayed (more than 6-24 hours of age) rescue therapy. Prophylactic surfactant was shown to be more effective than rescue treatments. With the increasing use of antenatal steroids and the routine use of NCPAP in the delivery room to establish functional residual capacity, use of prophylactic surfactant is no longer recommended. Prophylactic use of surfactant in infants at high risk of developing RDS does not lead to clinical improvement and may increase the risk of lung injury or death, when compared to early NCPAP and selective surfactant therapy [74]. Recently a synthetic surfactant, surfaxin, has been approved for prevention of RDS. This surfactant has not been evaluated for rescue management of RDS after stabilization with NCPAP. At the present time, there are no synthetic surfactants approved for use in rescue or selective surfactant therapy in preterm infants.

\section{Animal Derived Surfactants}

Animal derived surfactants are prepared from bovine or porcine lungs. The three most commonly available surfactants that are used worldwide are Beractant (BE), Calfactant (CA) and Poractant Alfa (PA). There are major biochemical differences between these three surfactants (Table 2). Beractant (Survanta) is an animal surfactant derived from minced bovine lung extract, with the added products of

\begin{tabular}{|c|c|c|c|c|c|c|c|c|c|c|c|}
\hline & \multicolumn{2}{|c|}{ PIP, $\mathrm{cm} \mathrm{H} \mathrm{H}_{2} \mathrm{O}$} & \multicolumn{2}{|c|}{ 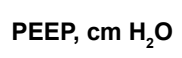 } & \multicolumn{2}{|c|}{ Inspiratory Time, s } & \multicolumn{2}{|c|}{ Rate, bpm } & \multirow{2}{*}{\begin{tabular}{|c|}
$\begin{array}{c}\text { Rise Time, } \% \text { or } \\
\text { number }\end{array}$ \\
Initial \\
\end{tabular}} & \multicolumn{2}{|c|}{ Flow rate, LPM } \\
\hline & Initial & Max & Initial & Max & Initial & Max & Initial & Max & & Max & \\
\hline Conventional Ventilator & 15 above PEEP & 30 & 5 & 8 & 0.5 & 0.5 & 40 & 50 & $5-9$ & 9 & $14-20$ \\
\hline Avea-NIV mode / Servoi- NIVPC & 15 above PEEP & 30 & 5 & 8 & 0.5 & 0.5 & 40 & 50 & $0.1-0.2$ & 0.2 & 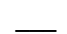 \\
\hline
\end{tabular}

NIPPV=Nasal Intermittent Positive Pressure Ventilation

Special Considerations: Bias Flow: 5 -8 LPM; Disconnect Sensitivity: 95\% or adjustable with Avea ventilator; Rise Time: When baby requires higher flow rates during spontaneous breathing, consider decreasing Rise Time Settings to allow higher PIFR. If available, leak compensation to be turned on. Heater is set at invasive mode, and if there is too much condensation, heater may be set at noninvasive mode for a few hours. Flow delivered at the nasal interface can be periodically checked with a proximal flow sensor. PIP and PEEP are weaned first before rate. IT with Si-PAP: Up to 1 second.

Weaning: When $\mathrm{FiO}_{2}$ is $<0.40, \mathrm{PCO}_{2}<60$ and $\mathrm{pH}>7.25$ :

- Wean PIP and then PEEP and Rate;

- $\quad$ Off NC-IMV when PIP $<10-12$, PEEP 5, Rate $\leq 20$ to NCPAP

- $\quad$ Off NCPAP when CPAP $\leq 5$ to Low Flow NC.

Table 1: Guidelines for starting and weaning during NIPPV/Nasal Cannula Intermittent Mandatory Ventilation (NC-IMV).

\begin{tabular}{|c|c|c|c|c|c|c|}
\hline Surfactant & Preparation & $\begin{array}{l}\text { Phospholipids } \\
\text { (mg/mL) }\end{array}$ & $\begin{array}{c}\text { DSPC } \\
(\mathrm{mg} / \mathrm{mL})\end{array}$ & $\begin{array}{l}\text { Total Proteins } \\
(\mathrm{mg} / \mathrm{mL})\end{array}$ & SP-B $(\mathrm{mg} / \mathrm{mL})$ & $\begin{array}{c}\text { PLMGN } \\
\text { (mol\% total PL) }\end{array}$ \\
\hline Poractant alfa (Curosurf) ${ }^{1}$ & $\begin{array}{c}\text { Minced porcine lung extract - purified via Liquid Gel } \\
\text { Chromatography }\end{array}$ & 76 & 30 & 1 & 0.45 & $3.8 \pm 0.1$ \\
\hline Beractant (Survanta) ${ }^{2}$ & $\begin{array}{l}\text { Minced bovine lung extract/ DPPC, Palmitic Acid, } \\
\text { Tripalmitin }\end{array}$ & 25 & $11-15.5$ & $<1$ & Not specified & $1.5 \pm 0.2$ \\
\hline Calfactant $^{\circledR}$ (Infasurf) $^{3}$ & Bovine Lung Lavage/DPPC, Cholesterol & 35 & 16 & 0.7 & 0.26 & Not specified \\
\hline
\end{tabular}

DSPC-disaturatedphosphatidylcholine, SP-B-surfactant protein B, SP-C-surfactant associated protein-C, PLMGN-plasmalogens

Table 2: Composition of animal derived surfactants. 
Dipalmitoylphosphatidylcholine (DPPC), palmitic acid and tripalmitin. Calfactant $\left(\right.$ Infasurf $\left.{ }^{\circledR}\right)$ is another bovine extract derived from lung lavages containing DPPC, and surfactant associated proteins, SP-B and SP-C. In contrast, $\mathrm{PA}$ (Curosurf ${ }^{\oplus}$ ) is extracted from minced porcine lungs and undergoes additional steps, including liquid gel chromatography. As a result, PA contains the highest amount of phospholipids, and SP-B. Furthermore, plasmalogens, which are antioxidant phospholipids, are also present in higher amounts in PA. Higher plasmalogen content in the tracheal aspirate in preterm infants is associated with a lower risk for developing BPD [75]. Higher amounts of DPPC also offers better anti-inflammatory properties [76], and down-regulates the respiratory burst via modulation of protein kinase C [77]. PA has been approved for use with an initial dose of $200 \mathrm{mg} / \mathrm{kg}$, and $100 \mathrm{mg} / \mathrm{kg}$ for subsequent doses, whereas, BE is used at $100 \mathrm{mg} / \mathrm{kg}$, and CA at $105 \mathrm{mg} / \mathrm{kg}$ for first and subsequent doses. Treatment with higher doses has been shown to result in lower BPD and mortality, less intraventricular hemorrhage, longer duration of action, faster weaning of oxygen, less air leaks, longer half-life, and less need for re-dosing [78-82]. The European consensus guidelines on the management of neonatal respiratory distress syndrome in preterm infants [83] recommend an initial dose of 200 $\mathrm{mg} / \mathrm{kg}$ dose of PA for the treatment of RDS, which is also endorsed by the European Association of Perinatal Medicine.

\section{Clinical Comparison of Animal Derived Surfactants}

Three randomized trials have been published comparing BE versus $\mathrm{CA}$ for prophylaxis and rescue treatment of RDS. Faster weaning of oxygen and mean airway pressure was reported with CA compared to $\mathrm{BE}$, and no differences in the need for additional doses, mortality or any other clinical outcomes were seen $[84,85]$. In contrast, comparison of porcine surfactant $\mathrm{PA}$, with bovine surfactant $\mathrm{BE}$ from 6 randomized trials, showed faster weaning of oxygen, faster weaning of PIP and mean airway pressure, fewer air leaks, less need for additional doses, less patent ductus arteriosus, less patients on invasive ventilation after 72 hours, and decreased the incidence of BPD and also reduced mortality [86-91]. Clark et al. [92] reported no difference in mortality between BE and CA in a retrospective study of 5,169 patients. Recently, Ramanathan et al. [93] in the largest retrospective study of 14,173 patients treated with $\mathrm{BE}$, $\mathrm{CA}$ and PA, reported $37 \%$ more likelihood of death with $\mathrm{BE}(\mathrm{p}=0.053)$, and $49.6 \%$ more likelihood of death with CA when compared to PA treatment. In a systematic review and meta-analysis, Singh et al. [94] reported similar findings of reduced mortality and shorter length of stay with PA as compared to BE. High amounts of DPPC, plasmalogens, SP-B, and polyunsaturated fatty acids contributing to lower viscosity, and phosphatidylcholine species resembling those in innate human surfactant may have been responsible for the beneficial effects seen with PA treatment. Based on evidence from randomized clinical studies and meta-analyses, PA appears to be the preferred animal derived surfactant for the selective treatment of RDS.

In summary, preterm infants needing respiratory support soon after delivery should be stabilized with NCPAP and or NIPPV. Sustained inflation may be used in infants who are not responding to NCPAP. Once stabilized, early, selective surfactant therapy should be given to infants meeting the criteria for RDS using the INSURE approach. Clinicians should begin NIPPV as soon as possible, preferably in delivery room, especially, in the ELBW infants, followed by weaning to NCPAP, and subsequently to low flow nasal cannula. Non-invasive ventilation and early, selective surfactant therapy may have a synergistic effect in decreasing bronchopulmonary dysplasia and associated adverse outcomes in preterm infants.

\section{References}

1. Stoll BJ, Hansen NI, Bell EF, Shankaran S, Laptook AR et al. (2010) Eunice Kennedy Shriver National Institute of Child Health and Human Development Neonatal Research Network. Neonatal outcomes of extremely preterm infants from the NICHD Neonatal Research Network. Pediatrics 126: 443-456.

2. Ramanathan R, Mason GR, Raj JU (1990) Effect of mechanical ventilation and barotrauma on pulmonary clearance of 99 mtechnetium diethylenetriamine pentaacetate in lambs. Pediatr Res 27: 70-74.

3. Dreyfuss D, Soler P, Basset G, Saumon G (1988) High inflation pressure pulmonary edema. Respective effects of high airway pressure, high tidal volume, and positive end-expiratory pressure. Am Rev Respir Dis 137: 11591164.

4. Hernandez LA, Peevy KJ, Moise AA, Parker JC (1989) Chest wall restriction limits high airway pressure-induced lung injury in young rabbits. J Appl Physiol 66: 2364-2368.

5. Kirby RR, Robison EJ, Schulz J, DeLemos R (1971) A new pediatric volume ventilator. Anesth Analg 50: 533-537.

6. Manginello FP, Grassi AE, Schechner S, Krauss AN, Auld PA (1978) Evaluation of methods of assisted ventilation in hyaline membrane disease. Arch Dis Child 53: 878-881.

7. Claure N, Bancalari E (2007) New modes of mechanical ventilation in the preterm newborn: evidence of benefit. Arch Dis Child Fetal Neonatal Ed 92: F508-F512.

8. Wheeler K, Klingenberg C, McCallion N, Morley CJ, Davis PG (2010) Volumetargeted versus pressure-limited ventilation in the neonate. Cochrane Database Syst Rev, CD003666. DOI: 10.1002/14651858.CD003666.pub3.

9. Thome UH, Carlo WA, Pohlandt F (2005) Ventilation strategies and outcome in randomised trials of high frequency ventilation. Arch Dis Child Fetal Neonatal Ed 90: F466-F473.

10. Cools F, Askie LM, Offringa M, Asselin JM, Calvert SA, et al. (2010) Elective high-frequency oscillatory versus conventional ventilation in preterm infants: a systematic review and meta-analysis of individual patients' data. Lancet 375 : 2082-2091.

11. Greenough A, Dimitriou G, Prendergast M, Milner AD (2008) Synchronized mechanical ventilation for respiratory support in newborn infants. Cochrane Database Syst Rev. CD000456. doi: 10.1002/14651858.CD000456.pub3.

12. Vogel V, Sheetz M (2006) Local force and geometry sensing regulate cell functions. Nat Rev Mol Cell Biol 7: 265-275.

13. Gharib SA, Liles WC, Klaff LS, Altemeier WA (2009) Noninjurious mechanical ventilation activates a proinflammatory transcriptional program in the lung Physiol Genomics 37: 239-248.

14. Bose CL, Laughon MM, Allred EN, O'Shea TM, Van Marter LJ, et al. (2013) Systemic inflammation associated with mechanical ventilation among extremely preterm infants. Cytokine 61: 315-322.

15. O'Shea TM, Allred EN, Kuban KC, Dammann O, Paneth N, et al. (2012) Elevated concentrations of inflammation-related proteins in postnatal blood predict severe developmental delay at 2 years of age in extremely preterm infants. J Pediatr 160: 395-401.

16. Gagliardi L, Bellù R, Zanini R, Dammann O, Network Neonatale Lombardo Study Group (2009) Bronchopulmonary dysplasia and brain white matter damage in the preterm infant: a complex relationship. Pediatr Perinatal Epidemiol 23: 582-590.

17. Bohrer B, Silveira RC, Neto EC, Procianoy RS (2010) Mechanical ventilation of newborns infant changes in plasma pro- and anti-inflammatory cytokines. $J$ Pediatr 156: 16-19.

18. Laughon MM, Langer JC, Bose CL, Smith PB, Ambalavanan N, et al. (2011) Prediction of bronchopulmonary dysplasia by postnatal age in extremely premature infants. Am J Respir Crit Care Med 183: 1715-1722.

19. Hillman NH, Moss TJ, Kallapur SG, Bachurski C, Pillow JJ, et al. (2007) Brief large tidal volume ventilation initiates lung injury and a systemic response in fetal sheep. Am J Respir Crit Care Med 176: 575-581.

20. Björklund LJ, Ingimarsson J, Curstedt T, John J, Robertson B, et al. (1997) Manual ventilation with a few large breaths at birth compromises the therapeutic effect of subsequent surfactant replacement in immature lambs. Pediatr Res 42: 348-355. 
21. Been JV, Rours IG, Kornelisse RF, Jonkers F, de Krijger RR, et al. (2010) Chorioamnionitis alters the response to surfactant in preterm infants. J Pediatr 156: 10-15.

22. Friedlich P, Lecart C, Posen R, Ramicone E, Chan L, et al. (1999) A randomized trial of nasopharyngeal synchronized intermittent mandatory ventilation versus nasopharyngeal continuous positive airway pressure in very low birth weight infants following extubation. J Perinatol 19: 413-418.

23. Ramanathan $R$ (2010) Nasal respiratory support through the nares: its time has come. J Perinatol 30 Suppl: S67-72.

24. Miller MJ, DiFiore JM, Strohl KP, Martin RJ (1990) Effects of nasal CPAP on supraglottic and total pulmonary resistance in preterm infants. J Appl Physiol 68: 141-146.

25. Harris H, Wilson S, Brans Y, Wirtschafter D, Cassady G (1976) Nasal continuous positive airway pressure. Improvement in arterial oxygenation in hyaline membrane disease. Biol Neonate 29: 231-237.

26. Harding R, Hooper SB (1996) Regulation of lung expansion and lung growth before birth. J Appl Physiol 81: 209-224.

27. Zhang S, Garbutt V, McBride JT (1996) Strain-induced growth of the immature lung. J Appl Physiol 81: 1471-1476.

28. Levesque BM, Kalish LA, LaPierre J, Welch M, Porter V (2011) Impact of implementing 5 potentially better respiratory practices on neonatal outcomes and costs. Pediatrics 128: e218-e226.

29. Courtney SE, Barrington KJ (2007) Continuous positive airway pressure and noninvasive ventilation. Clin Perinatol 34: 73-92, vi.

30. Pandit PB, Courtney SE, Pyon KH, Saslow JG, Habib RH (2001) Work of breathing during constant- and variable-flow nasal continuous positive airway pressure in preterm neonates. Pediatrics 108: 682-685

31. Stefanescu BM, Murphy W, Hansell BJ, Fuloria M, Morgan T et al. (2003) A randomized, controlled trial comparing two different continuous positive airway pressure systems for the successful extubation of extremely low birth weight infants. Pediatrics 112: 1031-1038.

32. Gupta S, Sinha SK, Tin W, Donn SM (2009) A randomized controlled trial of post-extubation bubble continuous positive airway pressure versus infant flow driver continuous positive airway pressure in preterm infants with respiratory distress syndrome. J Pediatr 154: 645-650.

33. Bober K, Swietlinski J, Zejda J, Kornacka K, Pawlik (2012) A multicente randomized controlled trial comparing effectiveness of two nasal continuous positive airway pressure devices in very-low-birth-weight infants. Pediatr Crit Care Med 13: 191-196

34. Kirpalani H, Millar D, Lemyre B, Yoder BA, Chiu A, et al. (2013) A trial comparing noninvasive ventilation strategies in preterm infants. N Engl J Med 369: 611620.

35. Davis P, Davies M, Faber B (2001) A randomised controlled trial of two methods of delivering nasal continuous positive airway pressure after extubation to infants weighing less than $1000 \mathrm{~g}$ : binasal (Hudson) versus single nasal prongs. Arch Dis Child ?Fetal Neonatal Ed 85: F82-F85.

36. Frey B, Shann F (2003) Oxygen administration in infants. Arch Dis Child Fetal Neonatal Ed 88: F84-F88.

37. Jasin LR, Kern S, Thompson S, Walter C, Rone JM, et al. (2008) Subcutaneous scalp emphysema, pneumo-orbitis and pneumocephalus in a neonate on high humidity high flow nasal cannula. J Perinatol 28: 779-781.

38. Siew ML, Te Pas AB, Wallace MJ, Kitchen MJ, Lewis RA, et al. (2009) Positive end-expiratory pressure enhances development of a functional residual capacity in preterm rabbits ventilated from birth. J Appl Physiol 106: 1487-1493.

39. Murthy V, Dattani N, Peacock JL, Fox GF, Campbell ME, et al. (2012) The firs five inflations during resuscitation of prematurely born infants. Arch Dis Child Fetal Neonatal Ed 97: F249-F253.

40. Perlman JM, Wyllie J, Kattwinkel J, Atkins DL, Chameides L, et al. (2010) Part 11: neonatal resuscitation: 2010 ?international consensus on cardiopulmonary resuscitation and emergency cardiovascular care science with treatment recommendations. Circulation 122: S516-S538.

41. Kattwinkel J, Perlman JM, Aziz K, Colby C, Fairchild K, et al. (2010) Part 15: neonatal resuscitation: 2010 American Heart Association guidelines for cardiopulmonary resuscitation and emergency cardiovascular care. Circulation 122: S909-S919.
42. Finer NN, Rich W, Wang C, Leone T (2009) Airway obstruction during mask ventilation of very low birth weight infants during neonatal resuscitation. Pediatrics 123: 865-869.

43. Schmo“Izer GM, Dawson JA, Kamlin CO, O'Donnell CP, Morley CJ, et al. (2011) Airway obstruction and gas leak during mask ventilation of preterm infants in the delivery room. Arch Dis Child ?Fetal Neonatal Ed 96: F254-F257.

44. van Vonderen JJ, Kleijn TA, Schilleman K, Walther FJ, Hooper SB, et al. (2012) Compressive force applied to a manikin's head during mask ventilation. Arch Dis Child Fetal Neonatal Ed 97: F254-F258.

45. Capasso L, Capasso A, Raimondi F, Vendemmia M, Araimo G, et al. (2005) A randomized trial comparing oxygen delivery on intermittent positive pressure with nasal cannulae versus facial mask in neonatal primary resuscitation. Acta Paediatr 94: 197-200.

46. Paz PF, Biniwale M, Hernandez R, Ramanathan R (2012) Primary neonata resuscitation using a specially designed nasal cannula in neonates: $A$ prospective observational study. Pediatr Res A4525.356.

47. Lindner W, Vossbeck S, Hummler H, Pohlandt F (1999) Delivery room management of extremely low birth weight infants: spontaneous breathing or intubation? Pediatrics 103: 961-967.

48. Lista G, Fontana P, Castoldi F, Cavigioli F, Dani C (2011) Does sustained lung inflation at birth improve outcome of preterm infants at risk for respiratory distress syndrome? Neonatology 99: 45-50.

49. te Pas AB, Walther FJ (2007) A randomized, controlled trial of delivery-room respiratory management in very preterm infants. Pediatrics 120: 322-329.

50. Dani C, Lista G, Pratesi S, Boni L, Agosti M, et al. (2013) Sustained lung inflation in the delivery room in preterm infants at high risk of respiratory distress syndrome (SLI STUDY): study protocol for a randomized controlled trial. Trials 14: 67

51. Morley CJ, Davis PG, Doyle LW, Brion LP, Hascoet JM, et al. (2008) Nasa CPAP or intubation at birth for very preterm infants. N Engl J Med 358: 700-708.

52. SUPPORT Study Group of the Eunice Kennedy Shriver NICHD Neonatal Research Network, Finer NN, Carlo WA, Walsh MC, Rich W, Gantz MG, et al (2010) Early CPAP versus surfactant in extremely preterm infants. N Engl J Med 362: 1970-1979.

53. Dunn MS, Kaempf J, de Klerk A, de Klerk R, Reilly M, et al. (2011) Randomized trial comparing 3 approaches to the initial respiratory management of preterm neonates. Pediatrics 128: e1069-e1076.

54. Tapia JL, Urzua S, Bancalari A, Meritano J, Torres G, et al. (2012) Randomized trial of early bubble continuous positive airway pressure for very low birth weight infants. J Pediatr 161: 75-80.

55. Greenough A, Morley CJ, Davis JA (1984) Provoked augmented inspirations in ventilated premature babies. Early Hum Dev 9: 111-117.

56. Chang HY, Claure N, D'ugard C, Torres J, Nwajei P, et al. (2011) Effects of synchronization during nasal ventilation in clinically stable preterm infants. Pediatr Res 69: 84-89.

57. Barrington KJ, Bull D, Finer NN (2001) Randomized trial of nasal synchronized intermittent mandatory ventilation compared with continuous positive airway pressure after extubation of very low birth weight infants. Pediatrics 107: 638 41.

58. Khalaf MN, Brodsky N, Hurley J, Bhandari V (2001) A prospective randomized controlled trial comparing synchronized nasal intermittent positive pressure ventilation versus nasal continuous positive airway pressure as modes of extubation. Pediatrics 108: 13-17.

59. Kugelman A, Feferkorn I, Riskin A, Chistyakov I, Kaufman B, et al. (2007) Nasal intermittent mandatory ventilation versus nasal continuous positive airway pressure for respiratory distress syndrome: a randomized, controlled, prospective study. J Pediatr 150: 521-26.

60. Moretti C, Giannini L, Fassi C, Gizzi C, Papoff P, et al. (2008) Nasal flowsynchronized intermittent positive pressure ventilation to facilitate weaning in very low-birth weight infants: unmasked randomized controlled trial. Pediatr In 50: 85-91.

61. Kishore MSS, Dutta S, Kumar P (2009) Early nasal intermittent positive pressure ventilation versus continuous positive airway pressure for respiratory distress syndrome. ActaPædiatrica 98: 1412-1415.

62. Lista G, Castoldi F, Fontana P, Daniele I, Cavigioli F, et al. (2010) Nasa continuous positive airway pressure (CPAP) versus bi-level nasal CPAP in 
preterm babies with respiratory distress syndrome: a randomised control trial. Arch Dis Child Fetal Neonatal Ed 95: F85-89.

63. Meneses J, Bhandari V, Alves JG, Herrmann D (2011) Noninvasive ventilation for respiratory distress syndrome: a randomized controlled trial. Pediatrics 127 : 300-307.

64. Ramanathan R, Sekar KC, Rasmussen M, Bhatia J, Soll RF (2012) Nasal intermittent positive pressure ventilation after surfactant treatment for respiratory distress syndrome in preterm infants <30 weeks' gestation: a randomized, controlled trial. J Perinatol 32: 336-343.

65. Bhandari V (2010) Nasal intermittent positive pressure ventilation in the newborn: review of literature and evidence-based guidelines. J Perinatol 30: 505-512.

66. Jatana KR, Oplatek A, Stein M, Phillips G, Kang DR, et al. (2010) Effects of nasal continuous positive airway pressure and cannula use in the neonata intensive care unit setting. Arch Otolaryngol Head Neck Surg 136: 287-291.

67. Fischer C, Bertelle V, Hohlfeld J, Forcada-Guex M, Stadelmann-Diaw C, et al. (2010) Nasal trauma due to continuous positive airway pressure in neonates. Arch Dis Child Fetal Neonatal Ed 95: F447-451.

68. Andaya S, Ramanathan R, Sardesai S, Cayabyab R, Garingo A, et al. (2010) Nasal respiratory support in preterm infants: A novel means of delivering timecycled, pressure and flow limited intermittent mandatory ventilation via nasal cannula. J Investig Med 58: A429.

69. Sinderby C, Beck J (2007) Neurally Adjusted Ventilatory Assist (NAVA): An update and summary of experiences. Neth J Crit Care 11: 243-252.

70. Stein H, Howard D (2012) Neurally adjusted ventilatory assist in neonates weighing <1500 grams: a retrospective analysis. J Pediatr 160: 786-789.

71. Lee J, Kim HS, Sohn JA, Lee JA, Choi CW, et al. (2012) Randomized crossover study of neurally adjusted ventilatory assist in preterm infants. J Pediatr 161 : 808-813.

72. Halliday HL (2008) Surfactants: past, present and future. J Perinatol 28 Supp 1: $\$ 47-56$

73. Ramanathan $R$ (2009) Choosing a right surfactant for respiratory distress syndrome treatment. Neonatology 95: 1-5.

74. Rojas-Reyes MX, Morley CJ, Soll R (2012) Prophylactic versus selective use of surfactant in preventing morbidity and mortality in preterm infants. Cochrane Database of Systematic Reviews: Plain Language Summaries DOI:10.1002/14651858.CD000510.pub2.

75. Rüdiger M, von Baehr A, Haupt R, Wauer RR, Rüstow B (2000) Preterm infants with high polyunsaturated fatty acid and plasmalogen content in tracheal aspirates develop bronchopulmonary dysplasia less often. Crit Care Med 28: 1572-1577.

76. Tonks A, Morris RH, Price AJ, Thomas AW, Jones KP, et al. (2001) Dipalmitoylphosphatidylcholine modulates inflammatory functions of monocytic cells independently of mitogen activated protein kinases. Clin Exp Immunol 124: 86-94.

77. Tonks A, Parton J, Tonks AJ, Morris RH, Finall A, et al. (2005) Surfactant phospholipid DPPC downregulates monocyte respiratory burst via modulation of PKC. Am J Physiol Lung Cell Mol Physiol 288: L1070-1080.

78. Konishi M, Fujiwara T, Naito T, Takeuchi Y, Ogawa Y, et al. (1988) Surfactan replacement therapy in neonatal respiratory distress syndrome. A multi-centre, randomized clinical trial: comparison of high- versus low-dose of surfactant TA. Eur J Pediatr 147: 20-25.

79. Speer CP, Robertson B, Curstedt T, Halliday HL, Compagnone D, et al. (1992) Randomized European multicenter trial of surfactant replacement therapy for severe neonatal respiratory distress syndrome: Single versus multiple doses of Curosurf. Pediatrics 89: 13-20
80. Halliday HL, Tarnow-Mordi WO, Corcoran JD, Patterson CC (1993) Multicentre randomised trial comparing high and low dose surfactant regimens for the treatment of respiratory distress syndrome (the Curosurf 4 trial). Arch Dis Child 69: 276-280.

81. Gortner L, Pohlandt F, Bartmann P, Bernsau U, Porz F, et al. (1994) High-dose versus low-dose bovine surfactant treatment in very premature infants. Acta Paediatr 83: 135-141.

82. Cogo PE, Facco M, Simonato M, Verlato G, Rondina C, et al. (2009) Dosing of porcine surfactant: effect on kinetics and gas exchange in respiratory distress syndrome. Pediatrics 124: e950-957.

83. Sweet DG, Carnielli V, Greisen G, Hallman M, Ozek E, et al. (2010) European consensus guidelines on the management of neonatal respiratory distress syndrome in preterm infants-2110 Update. Neonatology 97: 402-417.

84. Bloom BT, Kattwinkel J, Hall RT, Delmore PM, Egan EA, et al. (1997) Comparison of Infasurf (calf lung surfactant extract) to Survanta (Beractant) in the treatment and prevention of respiratory distress syndrome. Pediatrics 100: 31-38.

85. Bloom BT, Clark RH; Infasurf Survanta Clinical Trial Group (2005) Comparison of Infasurf (calfactant) and Survanta (beractant) in the prevention and treatment of respiratory distress syndrome. Pediatrics 116: 392-399.

86. Speer CP, Gefeller O, Groneck P, Laufkötter E, Roll C, et al. (1995) Randomised clinical trial of two treatment regimens of natural surfactant preparations in neonatal respiratory distress syndrome. Arch Dis Child Fetal Neonatal Ed 72 : F8-13

87. Baroutis G, Kaleyias J, Liarou T, Papathoma E, Hatzistamatiou Z, et al. (2003) Comparison of three treatment regimens of natural surfactant preparations in neonatal respiratory distress syndrome. Eur J Pediatr 162: 476-480.

88. Ramanathan R, Rasmussen MR, GerstmannDR, Finer N, Sekar K, et al. (2004) A randomized, multicenter masked comparison trial of poractant alfa (curosurf) versus beractant (survanta) in the treatment of respiratory distress syndrome in preterm infants. Am J Perinatol 21: 109-119.

89. Malloy CA, Nicoski P, Muraskas JK (2005) A randomized trial comparing beractant and poractant treatment in neonatal respiratory distress syndrome. Acta Paediatr 94: 779-784

90. Fujii AM, Patel SM, Allen R, Doros G, Guo CY, et al. (2010) Poractant alfa and beractant treatment of very premature infants with respiratory distress syndrome. J Perinatol 30: 665-670.

91. Dizdar EA, Sari FN, Aydemir C, Oguz SS, Erdeve O, et al. (2012) A randomized, controlled trial of poractant alfa versus beractant in the treatment of preterm infants with respiratory distress syndrome. Am J Perinatol 29: 95-100.

92. Clark RH, Auten RL, Peabody J (2001) A comparison of the outcomes of neonates treated with two different natural surfactants. J Pediatr 139: 828-831.

93. Ramanathan R, Bhatia JJ, Sekar K, Ernst FR (2013) Mortality in preterm infants with respiratory distress syndrome treated with poractant alfa, calfactant or beractant: a retrospective study. J Perinatol 33: 119-125.

94. Singh N, Hawley KL, Viswanathan K (2011) Efficacy of porcine versus bovine surfactants for preterm newborns with respiratory distress syndrome: systematic review and meta-analysis. Pediatrics 128: e1588-1595.
This article was originally published in a special issue, Controversies in the Management of Respiratory Distress Syndrome in Premature Neonates handled by Editor(s). Dr. Alan Fujii, Boston University, USA 